\title{
Sketch of Renewable Energy Production Simulation Platform
}

\author{
Jing Wang1, Yunfeng Gao', Yuehui Huang1, Yuefeng Wang1, Jietan Zhang2 \\ ${ }^{1}$ Renewable Energy Department, China Electric Power Research Institute, Beijing, China \\ ${ }^{2}$ Renewable Energy Department, Qinghai Power Grid Corporation, Xining, China \\ Email: wangjing@epri.sgcc.com.cn
}

Received 7 July 2015; accepted 15 October 2015; published 22 October 2015

\begin{abstract}
Renewable Energy Production Simulation Platform (REPS) is developed by China Electric Power Research Institute (CEPRI) to simulate the operation of renewable energy in the power system. REPS takes into account the characteristics of China's electric power system, it can assess the accommodation of renewable energy power and simulate the impact of different renewable energy capacity on the operation of power system. Assessment model and calculation process of REPS V1.3 is introduced in this article, and annual consumptive capacity in one provincial power grid of China is evaluated with the platform. REPS is of great guiding significance to electrical source planning. With the sustained and rapid growth of renewable energy in China, power system will be more and more dependent on REPS.
\end{abstract}

\section{Keywords}

\section{REPS, Renewable Energy, Simulation, Accommodation, Electrical Source Planning}

\section{Introduction}

Recent years, renewable energy such as wind power and photovoltaic (PV) power is emerging vigorously in the world, but due to wind power and PV power has the fluctuation and intermittence [1]-[3], and as the main electrical source of China, coal-fired power unit is not flexible when starting and stopping, the network structure of North China where renewable energy is centralized accessed is relatively weak, the accommodation of renewable energy power is becoming more and more prominent since 2010, wind/PV curtailment has become the point problem in the field of renewable energy. Researchers, engineers and power system operators are very concerned about the assessment of renewable energy power accommodation, related simulation tool is urgently required to simulate the operation of renewable energy in the power system.

The majority of wind power developed countries and regions have carried out research on the accommodation of renewable energy power [4]-[9]. The research methods can be divided into two categories: 1) Typical day analysis method, considering accommodation of renewable energy power in the worst cases to determine the maximum renewable energy capacity in the system; 2) the assessment of accommodation of renewable energy power, e.g. the Balmorel model developed in Denmark. China Electric Power Research Institute (CEPRI) began 
to research the accommodation of renewable energy power since 2006. After years of research and practice, the Renewable Energy Production Simulation Platform (REPS) has been developed which takes into account the situation of China. REPS is of great guiding significance to electrical source planning, With the sustained and rapid growth of renewable energy in China, power system will be more and more dependent on REPS.

REPS regards the maximum accommodation of renewable energy power as the optimization goal, can simulate the operation of all electrical sources and load in different situations. The main features of the renewable energy production simulation platform can be summarized as follow:

- Simplify the aggregation of the power network without influencing the calculation results, and the grid uses graphical polymerization modeling method which is intuitive and convenient.

- Basic data and running mode is managed by the mode of network-source-load, facilitating the operators to understand data and modes.

- The software is developed according to the three structures of basic data and operation mode, case calculation, calculation result and analysis, users can easily establish grid data to calculate and analyze, and all data can be shared without repeating the input operation.

- The software has batch computing function, users can easily submit multiple computing cases and calculate all the results at one time to avoid waiting a long time.

- The software is scalable, "plug and play" management mode is used in the case calculation model, facilitating the expansion of the software model.

\section{Assessment Model of Renewable Energy Accommodation}

\subsection{Grid Model}

The provincial power grid in China usually contains hundreds of substations and thousands of buses. Considering the physical model of whole power network is too complex, while the actual power grid is often radial, and the new energy station mainly connected to the terminal grid, there will not be many lines overload after the optimization of power network structure, so the aggregation grid model can be used to meet the requirements of the time series simulation. The aggregation model of power grid is shown in Figure 1.

Region A, B and C are renewable energy blocked areas which restricted by the cross section, the aggregation model is established based on the principles: a) aggregation model does not consider the detailed topological structure of the power grid, the power source and load are not affected by their physical location; b) the power consumption balance of the power network is not affected by the power network aggregation model.

\subsection{Thermal Power Unit Model}

Thermal power plant is an important member of the power system in China. It is very important for the accommodation of renewable energy. Thermal power units can be divided into condensing steam turbine, backpressure turbine and extraction turbine. Condensing steam turbine is exclusively for power generation, while back pressure turbine and pumping turbine can also heat, heating unit has greater influence on the accommodation of renewable energy.

1) Back pressure turbine

Back pressure turbine is a kind of heating units, its working characteristics are shown as Equation (1) and Figure 2(a). $C_{b}$ is the ratio of the power output and the thermal output of the unit, $H_{i, t}$ is the thermal output of the unit, $P_{i, t}$ is the power output of the unit.

$$
P_{i, t}=H_{i, t} \cdot C_{b}
$$

2) Pumping turbine

The working characteristics of pumping turbine are shown as Equation (2) and Figure 2(b). When the heat output is fixed, power output can be in a certain range which is decided by $C_{b}$ and $C_{v}$. $S_{i}^{M x}$ and $S_{i}^{E x}$ is the minimum and maximum power output.

$$
\left\{\begin{array}{l}
P_{i, t} \geq S_{i}^{M x}+H_{i, t} \cdot C_{b} \\
P_{i, t} \leq S_{i}^{E x}-H_{i, t} \cdot C_{v}
\end{array}\right.
$$




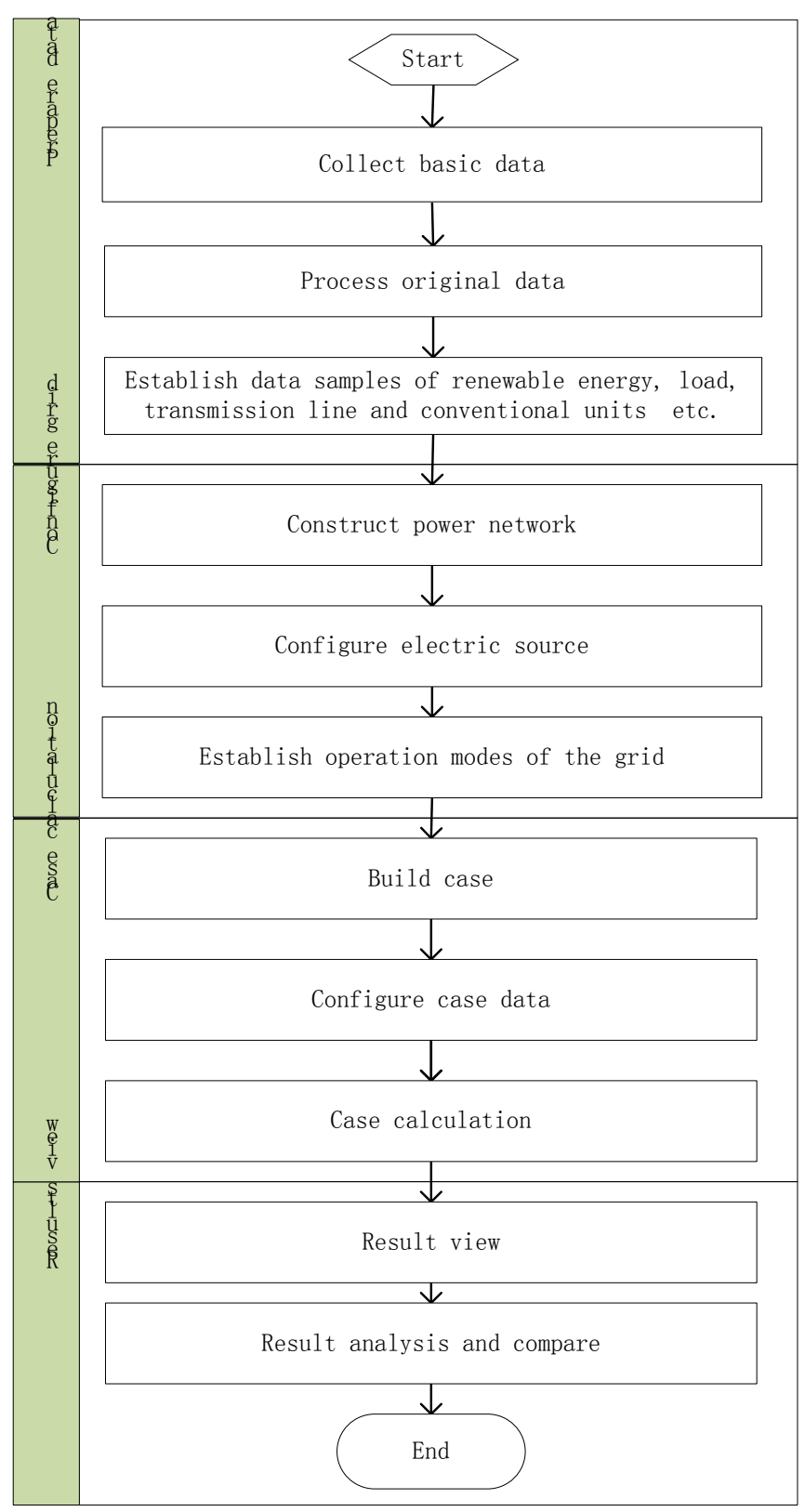

Figure 1. Simulation and calculation process.

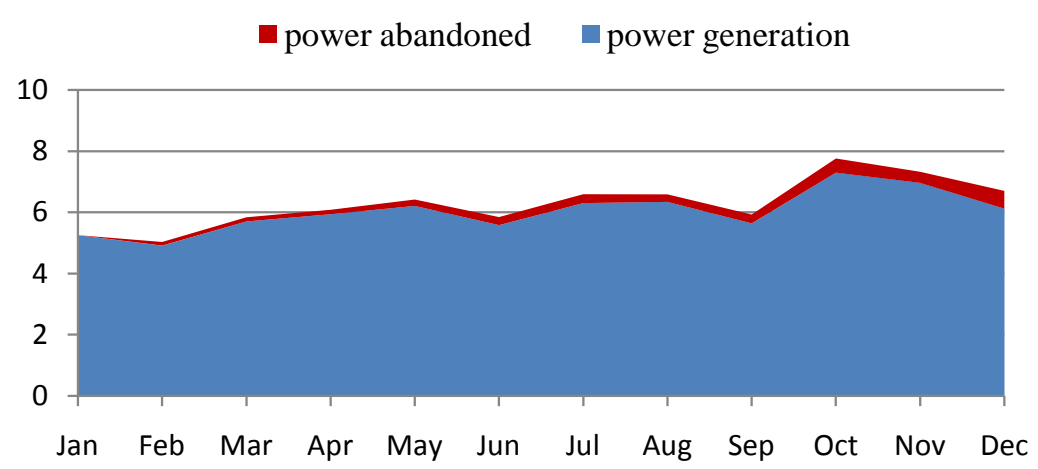

Figure 2. Consumptive capacity assessment of the model province. 


\subsection{Hydropower Unit Model}

Hydroelectric power plant can be divided into two categories, one is the run-off hydropower plant without capacity of regulation, and one is adjustable hydropower plant with adjustable reservoir. The operation of hydropower plant is closely related to water resources. Power generation of the run-off hydropower plant is basically determined by the flow of the river. Adjustable hydropower plant does not have minimum output limit, but reservoir inflow and reservoir capacity is the limit factors of the power output as shown in Equation (3).

$$
\left\{\begin{array}{l}
W_{s}+W_{\text {in }}-\sum_{t} P_{t}^{\text {rese }} \geq W_{s+1} \\
W_{\min } \leq W_{s} \leq W_{\max }
\end{array}\right.
$$

$W_{s}$ is the initial power generation capacity of the reservoir, $W_{i n}$ is the power generation capacity of the inflow water, $\sum_{t} P_{t}^{r e s e}$ is the actual power output, $W_{s+1}$ is the initial power generation capacity of the reservoir in next cycle, $W_{\min }$ and $W_{\max }$ is minimum and maximum power generation capacity of the reservoir.

\subsection{Renewable Energy Model}

The output of renewable energy can be viewed as time sequence in time series production simulation. The change characteristics of the sequence should be consistent with the actual renewable energy resources.

\subsection{Optimization Model}

\section{1) Optimization Objective}

REPS regards the maximum accommodation of renewable energy power as the optimization goal, considering renewable energy output is different in different locations, so renewable energy is calculated separately for different power grid, As shown in Equation (4):

$$
\max \sum_{t=1}^{T} \sum_{n=1}^{N}\left(P_{w}(t, n)+P_{p v}(t, n)\right)
$$

$N$ is the total number of aggregation networks in the system, $n$ is expressed as an aggregation power network, $T$ is the total simulation time, $t$ is the step, $P_{w}(t, n)$ and $P_{p v}(t, n)$ is the wind power and PV power output of network $n$ at time $t$.

3) Constraint Equations

Constraint Equations include reserve capacity constraint in Equation (5), load balance constraint in Equation (6), conventional unit output constraint in Equation (7)-(10), number of running units constraint in Equation (11), conventional unit power constraint in Equation (12) and regional transmission capacity constraint in Equation (13).

$$
\begin{aligned}
& \left\{\begin{array}{l}
\sum_{n=1}^{N} \sum_{j=1}^{J}\left(-P_{j, \text { max }}(t, n) \cdot S_{j}(t, n)-P_{w}(t, n)-P_{p v}(t, n)\right) \leq-\sum_{n=1}^{N} P_{l}(t, n)-P_{r e} \\
\sum_{n=1}^{N} \sum_{j=1}^{J}\left(P_{j, \min }(t, n) \cdot S_{j}(t, n)+P_{w}(t, n)+P_{p v}(t, n)\right) \leq \sum_{n=1}^{N} P_{l}(t, n)-N_{r e}
\end{array}\right. \\
& \sum_{j=1}^{J} P_{j}(t, n) \cdot S_{j}(t, n)+P_{w}(t, n)+P_{p v}(t, n)+L_{i}(t)=P_{l}(t, n) \\
& 0 \leq \Delta P_{j}(t, n) \leq\left[P_{j, \text { max }}(t, n)-P_{j, \text { min }}(t, n)\right] \cdot S_{j}(t, n) \\
& P_{j}(t, n)=P_{j, \min }(t, n) \cdot S_{j}(t, n)+\Delta P_{j}(t, n) \\
& P_{j}(t+1, n)-P_{j}(t, n) \leq \Delta P_{j, u p}(n) \\
& P_{j}(t, n)-P_{j}(t+1, n) \leq \Delta P_{j, \text { down }}(n) \\
& 0 \leq S_{j}(t, n) \leq S_{j \text { max }}(t, n)
\end{aligned}
$$




$$
\begin{gathered}
E_{j, \min } \leq \sum_{t=1}^{T} P_{j}(t, n) \Delta T \leq E_{j, \max } \\
-L_{i, \min } \leq L_{i}(t) \leq L_{i, \max }
\end{gathered}
$$

$P_{r e}$ and $N_{r e}$ is the positive and negative reserve capacity. $S_{j \cdot \max }(t, n), P_{j, \text { max }}(t, n)$ and $P_{j, \min }(t, n)$ is the total number, maximum and minimum output of unit $j$ in network $n$ at time $t . \Delta P_{j}(t, n)$ and $S_{j}(t, n)$ is the optimized power and running number of unit $j$ in network $n$ at time $t . P_{l}(t, n)$ is the system load of network $n$ at time t. $\Delta P_{j, \text { up }}(n)$ and $\Delta P_{j, \text { down }}(n)$ is the up and down ramp rate. $L_{i}(t)$ is the transmission power of line $i$ in network $n$ at time $t . \quad L_{i, \max }$ and $L_{i, \min }$ is maximum and minimum transmission capacity of line $i$.

\section{Simulation and Calculation Process}

The process of renewable energy production simulation is shown below:

\section{Annual Consumptive Capacity Assessment}

In the calculation of cases which based on the actual data and methods, REPS has shown the accuracy and practicability. In this paper, annual consumptive capacity of one model provincial power in China is elevated with the platform.

In the past year, accommodation of renewable energy in the model province is not effected by peak constraint, the main limiting factor is the channel stability limits, and there are two renewable energy channels in the west region, the restricted region of renewable energy accommodation is in mainly in west. The neighboring province needs transmission power from the model province in summer.

\subsection{Boundary Conditions of Renewable Energy Accommodation Calculation}

The boundary conditions of power grid operation is an important basis for the calculation of the renewable energy accommodation, the boundary conditions mainly include reserve capacity, conventional power supply mode, maximum and minimum technical output of the units, load data, renewable energy output sequence and transmission line principles. Boundary conditions of renewable energy accommodation calculation in the model province are shown in Table 1.

\subsection{Calculation Results}

In the annual assessment calculation of the next year, assuming the stability limit of the renewable energy channel is same with the previous year, and large-scale hydropower station will be put into operation in neighboring province, the installed renewable energy capacity of the model province is expected to increase 24 percent yearon-year, and the power network structure has little change compared to last year, so the new energy transmission channel has no change. Prediction of renewable power accommodation of the model province is shown in Table 2.

The monthly consumptive capacity assessment of the model province is shown in Figure 2.

From the results of the simulation, we can find that the channel stability limits is the main limiting factor for renewable energy accommodation in the model province, sending ability is limited by the grid structure constraints, due to large-scale hydropower station will be put into operation in neighboring province, the neighboring province power no longer needs power from the model province in summer, so the situation of renewable energy curtailment will continue.

\section{Conclusion}

This paper introduces the assessment model and calculation process of REPS V1.3, and annual consumptive capacity of one provincial model power grid is evaluated with the platform. REPS regards the maximum accommodation of renewable energy power as the optimization goal, the main functions can be summarized as follows: 
Table 1. Boundary conditions of renewable energy accommodation calculation.

\begin{tabular}{|c|c|c|}
\hline Number & Boundary Condition & Calculation Principle \\
\hline 1 & Reserve capacity & $\begin{array}{l}\text { Max }\{5 \% \text { of the maximum load, maximum } \\
\text { capacity of the single unit within the network }\} \text {; } \\
\text { Predictive wind power deduce } 20 \% \text { installed } \\
\text { capacity to participate on power balance }\end{array}$ \\
\hline 2 & Conventional power supply mode & Minimum period for the unit start and stop is once a week \\
\hline 3 & $\begin{array}{l}\text { Maximum and minimum technical } \\
\text { output of the thermal power units }\end{array}$ & Minimum operating mode provided by Electric Supervision Bureau \\
\hline 4 & Load data & The same as the previous year \\
\hline 5 & $\begin{array}{l}\text { Constraint conditions of hydropower } \\
\text { units in electricity power balance }\end{array}$ & $\begin{array}{l}\text { Maximum and minimum technical output is determined } \\
\text { according to the actual operation requirements; utilization } \\
\text { hours is in accordance with average water year or nearly three years }\end{array}$ \\
\hline 6 & Annual renewable energy utilization hours & According to the average level of the past three years to calculate \\
\hline 7 & Renewable energy time sequence & $\begin{array}{l}\text { Renewable energy time sequence recovered } \\
\text { from actual output data of the previous year }\end{array}$ \\
\hline 8 & Transmission line principle & $\begin{array}{l}\text { Transmission line mode is fixed, arranged } \\
\text { respectively in different months }\end{array}$ \\
\hline
\end{tabular}

Table 2. Prediction of renewable power accommodation.

\begin{tabular}{cc}
\hline Title & Calculation Result \\
\hline Expected power generation (billion kWh) & 7.226 \\
Power generation increase by (\%) & +24.16 \\
Expected utilization hours (h) & 1520 \\
Utilization hours increase by (\%) & -4.34 \\
Expected renewable energy curtailment (billion kWh) & 0.324 \\
Renewablion & +260 \\
Expected renewable energy curtailment rate (\%) & 4.29 \\
Renewable energy curtailment rate increase by & +2.79 \\
\hline
\end{tabular}

- According to the historical operating characteristics of wind power and PV power, build the renewable energy time sequence which can be used for simulation calculation.

- In the case of known renewable energy capacity, simulates future renewable energy power output and power limit monthly and yearly.

- Simulates the impact of different renewable energy capacity on the operation of power system, including the starting and stopping power units, utilization hours and so on.

- With different conventional power startup modes and load regulation characteristics, simulates renewable energy power output and limit, the advice of renewable energy construction and the conventional power operation mode are proposed.

- Simulates renewable energy power output and limit with different system backup, proposed priority accommodation of renewable energy to the grid.

- Simulates development planning and layout optimization of the renewable energy, the advice of planning capacity and construction sites for renewable energy are proposed.

With the vigorously emerging renewable energy in China, REPS which takes into account the characteristics of China's electric power system will be more and more important in electrical source planning. 


\section{References}

[1] Chen, C.L. (2008) Optimal Wind-Thermal Generating Unit Commitment. IEEE Transactions on Energy Conversion, 23, 273-280. http://dx.doi.org/10.1109/TEC.2007.914188

[2] Marwali, M.K.C. and Shahidehpour, S.M. (2000) Coordination between Long-Term and Short-Term Generation Scheduling with Network Constraints. IEEE Transactions on Power Systems, 15, 1161-1167. http://dx.doi.org/10.1109/59.871749

[3] Handke, J., Handschin, E., Linke, K. and Sanders, H.-H. (1995) Coordination of Long- and Short-Term Generation Planning in Thermal Power Systems. IEEE Transactions on Power Systems, 10, 803-809. http://dx.doi.org/10.1109/59.387920

[4] Chen, C.L. (2007) Simulated Annealing-Based Optimal Wind-Thermal Coordination Scheduling. IET Generation, Transmission \& Distribution, 1, 447-455. http://dx.doi.org/10.1049/iet-gtd:20060208

[5] Handschin, E. and Slomski, H. (1990) Unit Commitment in Thermal Power Systems with Long-Term Energy Constraints. IEEE Transactions on Power Systems, 5, 1470-1477. http://dx.doi.org/10.1109/59.99401

[6] Grothe, O. and Schnieders, J. (2011) Spatial Dependence in Wind and Optimal Wind Power Allocation: A CopulaBased Analysis. Energy Policy, 39, 4742-4754. http://dx.doi.org/10.1016/j.enpol.2011.06.052

[7] Decarolis, J.F. and Keith, D.W. (2007) The Economics of Large-Scale Wind Power in a Carbon Constrained World. Energy Policy, 35, 3999-4008.

[8] Liang, R.H. and Liao, J.H. (2007) A Fuzzy-Optimization Approach for Generation Scheduling with Wind and Solar Energy Systems. IEEE Transactions on Power Systems, 22, 1665-1674. http://dx.doi.org/10.1109/TPWRS.2007.907527

[9] Lee, T.Y. (2007) Optimal Spinning Reserve for a Wind-Thermal Power System Using EIPSO. IEEE Transactions on Power Systems, 22, 1612-1621. http://dx.doi.org/10.1109/TPWRS.2007.907519 